\title{
Effect of Heat-Treating on Microstructure and High Cycle Bending Fatigue Behavior of AZ91 and AZE911 Magnesium Alloys
}

\author{
Ahmad Yousefi Parchin Oliya, ${ }^{1}$ Mohammad Azadi $(1)$, \\ Mohammad Sadegh Aghareb Parast, ${ }^{2}$ and Mehdi Mokhtarishirazabad ${ }^{3}$ \\ ${ }^{1}$ Faculty of Aerospace Engineering, Semnan University, Semnan, Iran \\ ${ }^{2}$ Faculty of Mechanical Engineering, Semnan University, Semnan, Iran \\ ${ }^{3}$ Department of Mechanical Engineering, University of Bristol, Bristol, UK \\ Correspondence should be addressed to Mohammad Azadi; m_azadi@semnan.ac.ir
}

Received 23 October 2021; Revised 18 January 2022; Accepted 25 January 2022; Published 2 March 2022

Academic Editor: Akbar Heidarzadeh

Copyright (c) 2022 Ahmad Yousefi Parchin Oliya et al. This is an open access article distributed under the Creative Commons Attribution License, which permits unrestricted use, distribution, and reproduction in any medium, provided the original work is properly cited.

\begin{abstract}
This article investigates the influences of heat-treating on the microstructures and the high cycle fatigue (HCF) properties of AZ91 and AZE911 (AZ91 + 1\%RE) magnesium alloys. For such an objective, AZ91 and AZE911 alloys were used after solution treatment at $415^{\circ} \mathrm{C}$ for 5 hours aged at $215^{\circ} \mathrm{C}$ for 3 hours and at $215^{\circ} \mathrm{C}$ for 5 hours, respectively. To investigate the HCF behavior, a rotational bending fatigue test was performed with stress ratio $(R)-1$ and frequency of $100 \mathrm{~Hz}$ at room temperature. Optical microscopy $(\mathrm{OM})$ study demonstrates that heat treatment leads to a reduction in grain size and transformation of continuous and discontinuous precipitations into needle-shaped precipitations, which are located on the grains of the alpha phase. Scanning electron microscopy (SEM) showed both marks of quasicleavage and cleavage on the fracture surface of specimens. These planes indicated the brittle behavior of the fracture. Moreover, in heat-treated specimens, the size of cleavage patterns was smaller, and microcracks were shorter. These behaviors affected the strength of the material and the fatigue lifetime. The results of mechanical tests show a negligible influence of heat-treating on the HCF behaviors of AZ91-T6 and AZE911-T6 alloys. Stress-lifetime curves (S-N) show an increase in fatigue strength in $3.8 \times 10^{5}$ fatigue cycles, from $95 \mathrm{MPa}$ to $125 \mathrm{MPa}$ for the AZ91-T6 alloy and from $125 \mathrm{MPa}$ to $155 \mathrm{MPa}$ for the AZE911-T6 alloy, after heat treatment.
\end{abstract}

\section{Introduction}

Magnesium alloys are lightweight materials that are used in the automotive and aerospace industries due to their high strength-to-weight ratio and good vibration damping [1] and proper thermal conductivity $[2,3]$. Most of the components produced by these alloys are under cyclic loadings through a high cycle regime, which causes the fatigue phenomenon. The AZ91D alloy including 9 wt.\% of aluminum and $1 \mathrm{wt} . \%$ of zinc is the most used magnesium alloy in the automotive industry, due to great casting ability, good corrosion resistance, and well room/low temperature mechanical performance. Nevertheless, the weak fatigue strength under high forces or stresses limited the applications of the AZ91D alloy [4]. Thus, the improvement of the fatigue properties of magnesium alloys is the most important objective of many researchers, which is discussed as a literature review, below.

Wenwen et al. [5] investigated the weaknesses of the mechanical properties of the AZ91 alloy. They showed that reducing of mechanical properties in AZ91 under high-stress levels and temperature conditions was due to the softening behavior of the intermetallic phase $\left(\mathrm{Mg}_{17} \mathrm{Al}_{12}\right)$. Mahmudi et al. [6] presented the effects of $2 \mathrm{wt} \%$ rare earth elements (RE) additions and annealing process (T4) on the structure and shear strength of AZ91. They reported that stability and shear strength are improved by reducing the volume fraction of the $\beta$ phase $\left(\mathrm{Mg}_{17} \mathrm{Al}_{12}\right)$, which could inhibit grain growth during the annealing process (T4) at $420^{\circ} \mathrm{C}$. Kuffova [7] depicted the influence of heat-treating on the HCF 
properties of magnesium alloys and reported that the rate of fatigue crack growth depends on the stress intensity factor, which increased with enhancing the asymmetry coefficient. The crack growth could be decreased because of ageing (T6) and could be enhanced after the dissolution of annealing (T4). Bag and Zhou [8] investigated the HCF behavior of the AZ91D-T6 alloy. They claimed that the high fatigue crack propagation resistance is more due to the larger deviation of the crack path from the maximum stress planes to many branches in the heat-treated material, which decreased the effective stress intensity at the crack tip, resulting in a lower crack growth rate. Zhang et al. [9] compared the straincontrolled behavior of NZ30K-T6 and AZ91D-T6 magnesium alloys. They demonstrated that increasing the strength of the matrix could increase the resistance of the matrix to the dislocation movement and the slip bands formation. Hassan and Lewandowski [10] evaluated the effect of adding Silicon Carbide-nanoparticles and T4/T6 heat treatments on the fatigue lifetime of AZ91D. They claimed that, for both heat treatments, the samples did not fail in the range of $10^{6}-10^{7}$ cycles. For that region, the AZ91D alloy with T6 heat treatment showed better fatigue properties compared to T4. Dobrzanski et al. [11] characterized the influences of ageing and solution on the microstructure of MgAl9Zn1. They showed that the solution formed the $\beta$ phase $\left(\mathrm{Mg}_{17} \mathrm{Al}_{12}\right)$ in the form of planes that were mostly at the grain boundary and the ageing formed the precipitations of $\beta$ phase to be evenly distributed in the needle shape on the grains of the alpha phase. Horstemeyer et al. [12] presented the effect of different T4/T6 treatments on the microstructure of the AZ91 alloy. They indicated that cast and dissolved samples had cyclic hardening, which can generally be due to increased dislocation density, and the aged samples exhibited nonuniform behavior during microplastic deformation. Govindaraju et al. [13] illustrated the effect of heat-treating and FSP on the AZ91D alloy. They indicated that crack growth at high-stress levels changed from continuous to discontinuous mode under the influence of heat-treating. FSP had better effects on fatigue lifetime compared to the heat-treating process. Leo Prakash et al. [14] characterized the effects of long-term annealing (T4) and ageing (T6) on precipitates in the microstructure of magnesium alloys. They showed that the aged $\mathrm{Mg}-\mathrm{RE}$ and $\mathrm{Mg}-\mathrm{Zn}$ alloys had cyclic softening behavior due to the presence of cohesive precipitates, which could be easily cut by dislocations. Conversely, the aged $\mathrm{Mg}-\mathrm{Al}$ alloys formed inconsistent precipitates. Suman [15] evaluated the crack behavior in AZ91D-T6 and AM60B-T6 Mg alloys. They found that the rate of crack propagation significantly depends on the microstructure and microstructural constituents. In the AM60B-T6 alloy, the precipitates caused the decelerating influence on the crack propagation rate, while in the AZ91D-T6 alloy, the $\mathrm{Mg}_{17} \mathrm{Al}_{12}$ phase did so. Dimitrov and Shtarbakov [16] examined the HCF ultrasonic test of the AZ91 alloy. They reported that fatigue cracks were created from existing microcracks in the phase boundary between $\beta$ phase precipitations $\left(\mathrm{Mg}_{17} \mathrm{Al}_{12}\right)$ and the main $\alpha$-Mg matrix. Heat-treating to resolve these precipitations could increase the strength of the AZ91 alloy. Mayer et al. [17] presented the strength limit, stress intensity of $\mathrm{Mg}$ and $\mathrm{Al}$ alloys and showed that the pores caused the cavities, blowholes, and microdeformations during heattreating. Li et al. [18] assessed the fracture surface of AZ91DT6. They observed that the crack growth area consisted mainly of fine facets and serrated fatigue striations inside the grains. Moreover, very small amounts of undissolved and cracked $\beta$ phase particles $\left(\mathrm{Mg}_{17} \mathrm{Al}_{12}\right)$ were observed on the fracture surface. In one research, Mokhtarishirazabad et al. [19] investigated the effect of rare earth elements (RE) on the HCF behavior of the AZ91 alloy. They found that the addition of $1 \% \mathrm{RE}$ improved the fatigue crack propagation resistance and fracture toughness of the AZ91 alloy, significantly. Moreover, they claimed that the addition of $1 \%$ RE improved the strength limit of (none-heat-treated) AZ91 as much as A319-T6 and A356-T7 aluminum (cylinder head) alloys, at the same fatigue lifetime range $\left(10^{4}-10^{6}\right.$ cycles). Rezanezhad et al. [20] studied the effect of heattreating on HCF and fracture behaviors of aluminum-silicon alloys. The HCF lifetime improved by heat-treating, significantly under both the highest and lowest stress levels. Azadi et al. [21] investigated the thermomechanical fatigue behaviors of the AZE911 magnesium alloy, considering T6 heat-treating. They found an effective difference in the lifetime of the AZE911 alloy when the heat treatment was applied. Lee et al. [22] analyzed the effects of Y, Sr, and $\mathrm{Nd}$ additives and heat treatment on the hardness and microfracture mechanism of the AZ91 alloy. They found that the in-situ fracture of an AZ91-Sr-T6 alloy, coarse needle composed particles, and the $\mathrm{Mg}_{17} \mathrm{Al}_{12}$ phase at the grain boundary provided an easy intergranular fracture site under low-stress intensity factor levels, thereby reducing toughness. Moreover, in AZ91-Y-T6 and AZ91-Nd-T6 alloys, the fracture toughness improved. Khisheh et al. [23] analyzed the effects of the roughness and heat-treating on HCF behaviors of A380. Through cyclic loading, they claimed that, under the highest and lowest stress levels, heat-treating improved the HCF lifetime by $26 \%$ and $85 \%$, respectively. Azadi et al. [24] depicted the effects of heat-treating on the microstructure of cylinder head material. They claimed that heat-treating could affect the microstructure and led to the uniform distribution for silicon and intermetallic phases.

As a result of reviewing the literature, researchers have tested many approaches to enhance the mechanical and fatigue properties of magnesium alloy cylinders and cylinder heads such as different types of heat treatment [7-12,14,16-18,20-23], FSP [13], the addition of rare earth elements [4,6,19-23], the addition of nanoparticles $[10,20,24]$, and so on. In addition, investigation of the HCF properties of heat-treated AZ91 and AZE911 alloys is still rare. Therefore, the use of heat treatment to improve the HCF behavior in these magnesium alloys could be a novelty of this research.

\section{Tests and Materials}

The studied materials included AZ91 and AZE911 (AZ91 + 1\%RE) magnesium alloys. To improve the material properties of AZ91, RE elements were added to the melt. Therefore, the composition of the Ce-rich MM (Misch 
Metal) plus AZ91 was made by melting in the steel crucible. This job was done under the controlled environment of $\mathrm{CO}_{2}+1 \%$ HFC- (Hydrofluorocarbon-) 134a at the temperature of $750 \pm 5^{\circ} \mathrm{C}$ for 30 minutes, in the furnace. Moreover, RE elements included $67 \% \mathrm{Ce}, 23 \% \mathrm{La}, 7 \% \mathrm{Pr}$, and $2 \% \mathrm{Nd}$. To have a uniform distribution, the melt was stirred for 1 minute, by the mild steel rod. Then, the casting process was carried out in the preheated bottom-filled steel die, whose temperature was around $200^{\circ} \mathrm{C}$. Finally, Table 1 illustrates the chemical composition of studied magnesium alloys.

Based on the objective of metallographic studies, samples were etched in an acetic glycol solution. The etchant included $60 \mathrm{ml}$ ethylene glycol, $20 \mathrm{ml}$ acetic acid, $20 \mathrm{ml}$ water, and $1 \mathrm{ml} \mathrm{HNO}_{3}$.

After casting, the standard samples of fatigue testing were machined based on the ISO-1143 standard, as depicted in Figure 1.

Before the HCF tests, the machined cylindrical-shaped specimens were solution-treated at $415^{\circ} \mathrm{C}$ for 5 hours, and then the AZ91 and AZE911 alloys aged at $215^{\circ} \mathrm{C}$ for 3 hours and $215^{\circ} \mathrm{C}$ for 5 hours, respectively. The samples were solutionized and aged in an ATE1100L horizontal tubular furnace from the ATRA Company, under the $\mathrm{CO}_{2}$ gascontrolled atmosphere to prevent the alloys from surface oxidation. The hardness test was performed by the Brinell method (using the universal hardness tester, model UV1 from KOOPA Company) according to the ASTM-E10-14 standard with a steel ball indenter, whose diameter is $10 \mathrm{~mm}$ under a force of $1500 \mathrm{~kg}$, repeated up to four times. HCF tests were conducted under four or five stress levels for AZ91-T6 and AZE911-T6 alloys with a STF-600 2-point rotational bending fatigue tester from the SANTAM Company, under fully reversed cyclic bending loads with the stress ratio of -1 and through $100 \mathrm{~Hz}$ of the loading frequency. The endurance limit of the sample was considered as $10^{6}$ cycles or until the full fracture of the specimen.

To evaluate the failure mechanisms for the fatigue crack, including both initiation and propagation, scanning electron microscopy (SEM), model VEGA3 from the TESCAN Company, fractography was used on the fracture surface of specimens, with aided energy-dispersive X-ray spectroscopy (EDS) to find elements. The changes of phases and precipitations in the microstructures of AZ91 and AZE911 alloys were observed before and after heat treatment by optical microscopy (OM). The microstructures of the samples have been observed in the optical microscopy, HMLUX model from the Leitz Company.

In order to have a summarized information on all testing, samples, and studied materials, Table 2 is presented.

\section{Results and Discussion}

Figure 2 shows the effects of heat-treating on the microstructure of AZ91 and AZE911 alloys. The alloy microstructure consisted of the $\alpha$-Mg solid solution (matrix or alpha phase), the grain boundary, the interdendritic eutectic $\beta$ phase $\left(\mathrm{Mg}_{17} \mathrm{Al}_{12}\right)$, and the needle-shaped precipitates due to the transformation of $\beta\left(\mathrm{Mg}_{17} \mathrm{Al}_{12}\right)$ precipitates during the ageing process. Heat-treating led to two distinct influences on the microstructure of AZ91 and AZE911 alloys. The first effect was the transformation of continuous and discontinuous $\beta$ phase $\left(\mathrm{Mg}_{17} \mathrm{Al}_{12}\right)$ precipitations at the grain boundary to needle-shaped precipitations on $\alpha$-Mg phase grains, which was the most effective factor in increasing the hardness. The second effect was the reduction of grain size from $300 \mu \mathrm{m}$ to $130 \mu \mathrm{m}$ for the AZ91 alloy and from $230 \mu \mathrm{m}$ to $90 \mu \mathrm{m}$ for the AZE911 alloy (using the ImageJ software), which caused a significant increase in the number of grain boundaries as well as the number of grains, which was the main reason for increasing the strength limit. Therefore, logical agreements could be seen compared to the literature for these microstructural changes by heat-treating $[8,18,25,26]$.

Bag and Zhou [8] examined optical micrographs of the cast, dissolved, and aged microstructures. In all casting, dissolved, and aged states, the $\beta$ phase $\left(\mathrm{Mg}_{17} \mathrm{Al}_{12}\right)$ can be seen at the grain boundary and the eutectic $\alpha$ phase is adjacent to the $\beta$ phase. Zhang et al. [9] demonstrated that the discontinuous precipitation of the $\beta$ phase $\left(\mathrm{Mg}_{17} \mathrm{Al}_{12}\right)$ occurs at the ageing temperature of $200^{\circ} \mathrm{C}$, where a layered structure is perpendicular to the base plane of the matrix, is nucleated at the grain boundary, and grew into the grain. Based on linear intercept, the average grain size of the AZ91-T6 alloy was about $135 \mu \mathrm{m}$ (for AZ91-T6, no significant difference was observed in mean grain size and grain size distribution). Figure 3 shows the effect of heat treatment on the hardness of AZ91 and AZE911 alloys. Ageing at $215^{\circ} \mathrm{C}$ for 3 hours increased the hardness of the AZ91 alloy from 67 to 108 Vickers (60\% improvement) and ageing at $215^{\circ} \mathrm{C}$ for $5 \mathrm{~h}$ increased the hardness of AZE911 from 76 to 115 Vickers (50\% improvement). Figure 4(a) shows all the HCF experimental data and compares the stress levels and fatigue cycles until failures (including S-N curves) for AZ91 and AZE911, before and after heat-treating. As shown in Figure 4, AZ91-T6 and AZE911-T6 alloys showed a premature failure under high-stress levels. Moreover, fracture assessments demonstrated that large porosities were responsible and effective for such a behavior. Figure 4(b) shows the average HCF lifetimes with the corresponding trend lines. It can be seen from Figure 4(b) that heat-treating had two prominent influences on the stress-lifetime curve. The first influence was to increase the fatigue strength of the material at each stress level and the second one was the fatigue behavior of AZ91-T6 and AZE911-T6, which was affected by two mentioned factors. The first factor was the grain size and the pore distribution, and the second factor was the size and precipitations of the intermetallic $\mathrm{Mg}_{17} \mathrm{Al}_{12}$ phase.

Enhancing the density of the grain boundary and distributing the tensile stress through more grains (in other words, lower stress concentrations per grain) results in a reduction of the grain size in the alloys. In addition, the propagation of fatigue cracks generally occurred along with the grain boundary or along with the $\beta$ phase in magnesium alloys. Thus, reducing the amount of interdendritic $\beta$ particles had a significant influence on the propagation of fatigue cracks in the case of intergranular fracture [19]. Experimental data showed that, for example, in $3.8 \times 10^{5}$ cycles, the fatigue strength of the AZ91 alloy increases from 
TABle 1: Alloy chemical compositions (wt. \%) in this research.

\begin{tabular}{lcccccc}
\hline Alloy & $\mathrm{Al}$ & $\mathrm{Zn}$ & $\mathrm{Mn}$ & $\mathrm{Ce}$ & $\mathrm{La}$ & $\mathrm{Mg}$ \\
\hline AZ91 & 9.43 & 0.93 & 0.19 & - & - & Balance \\
AZE911 & 8.84 & 0.81 & 0.14 & 0.64 & 0.33 & Balance \\
\hline
\end{tabular}

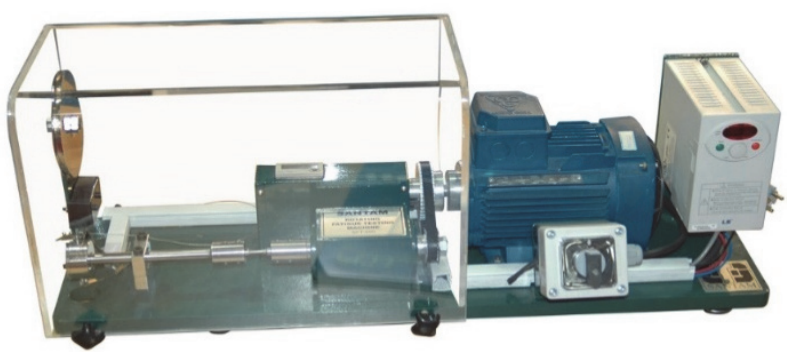

(a)

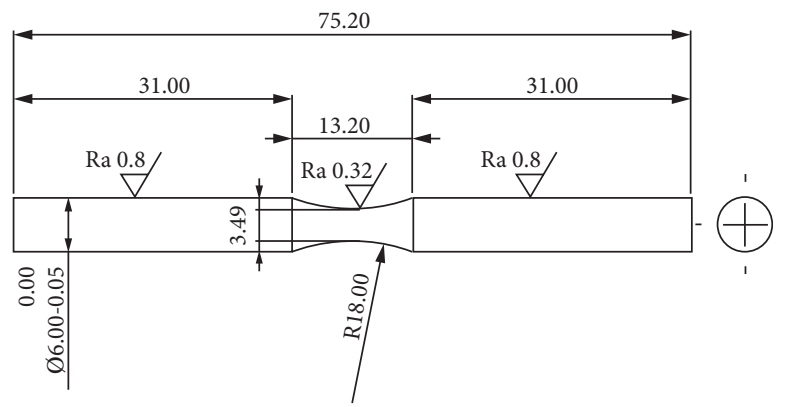

(b)

FIGURE 1: (a) The equipment for fatigue testing and (b) the geometry of fatigue specimens.

TABLE 2: Summarized information for testing and samples in this research.

\begin{tabular}{lcc}
\hline Materials & $\begin{array}{c}\text { Number of } \\
\text { samples }\end{array}$ & Stress amplitude (MPa) \\
\hline AZ91 & 11 & $64.6,74.5,84.7,94.6$, and 104.5 \\
AZE911 & 11 & $104.6,114.5,124.7,134.6$, and \\
AZ91-T6 & 13 & $114.5,124.5,134.6$, and 144.7 \\
AZE911- & 12 & $155.3,165.5,176.0$, and 185.7 \\
T6 & & \\
\hline
\end{tabular}

95 to $125 \mathrm{MPa}$ (31\% improvement) and fatigue strength of the AZE911 alloy from 125 to $155 \mathrm{MPa}$ (24\% improvement), after heat treatment. The feasibility of the replacement of the AZ91 alloy with the AZE911 alloy for the cylinder head in automotive engines by adding 1\% RE was discussed [19]. Now, it is shown that the mechanical properties and strength limit of the AZ91-T6 alloy are the same as the AZE911 alloy. This means that heat treatment has approximately the same effect as the addition of $1 \% \mathrm{MM}, 1 \% \mathrm{Ce}$, and $1 \% \mathrm{Nd}$ on the HCF behavior of AZ91. Figure 4(c) shows the rotational bending fatigue curves of the AZ91-T6 alloy in this and other studies. In Figure 4(c), some researchers reported the fatigue strength of heat-treated AZ91 in the range of $10^{4}-10^{6}$ cycles at $130-190 \mathrm{MPa}[7,10,20]$, while some others reported it at 60-120 MPa [9,16-18]. Xu et al. [28] claimed that 1\% MM addition has drastically reduced the grain size of beta phase (Mg17Al12) to $66 \mu \mathrm{m}$ and alpha phase to $16 \mu \mathrm{m}$ and reduced the size of dendritic cells, which has increased the fatigue limit by reducing the number of casting defects. Hassan and Lewandowski [10] reported similar results for grain size reduction after heat-treating of the AZ91-T6 alloy. Beside the grain size reduction, Dimitrov and Shtarbakov [16] claimed that heat treatment caused dissolving of precipitations on the $\alpha$-Mg phase in terms of improving the fatigue strength of the AZ91D alloy. There are reasonable agreements in the literature to change grain size after heat treatment $[8,9,18,30-33]$. From Figure $4(\mathrm{~d})$, the fatigue strengths of AZ91 + X\% Nd, AZ91 + X\% Ce, AZ91 + 1\% MM, and AZE911 alloys can be seen in the $10^{4}-10^{7}$ cycles range. Figure 4(d) shows that the strength limit of AZ91 + 1\% MM and AZ91 + X\% Nd alloys in the $10^{4}-10^{7}$ cycle is $70-90 \mathrm{MPa}$, the strength limit of the AZ91+X\% Ce alloy in the $10^{4}-10^{7}$ cycle is 100-120 MPa, and finally, the strength of the AZE911 alloy in the $10^{4}-10^{6}$ cycle is $105-145 \mathrm{MPa}$, which increased to 155-185 MPa after heat treatment. It means that the strength limit of heat-treated AZ91 containing rare earth elements (AZE911-T6) alloys is much higher than the none-heattreated $(\mathrm{AZ} 91+\mathrm{X} \% \mathrm{Ce}, \mathrm{AZ91}+\mathrm{X} \% \mathrm{Nd}$ and $\mathrm{AZ91}+1 \% \mathrm{MM}$ and $A Z 91+1 \% R E)$ alloys. In this research, the feasibility of using AZ91-T6 instead of A319-T6 and the replacement of AZE911-T6 instead of A356-T6 and A380-T6 aluminum alloys for the application in the cylinder head of diesel engines were discussed. Although the mechanical properties and the HCF strength of the AZE911-T6 alloy were lower than A356-T6 and A380-T6, it was still in the range of required data for such an application, and similarly, the same claim is true for replacing the AZ91-T6 alloy instead of A319-T6. In Figure 4(e), the HCF behavior of the AZ91-T6 magnesium alloy is compared to the A319-T6 aluminum alloy, and in Figure 4(f), the HCF behavior of the AZE911T6 magnesium alloy is compared to A356-T6 and A380-T6 aluminum alloys (the most commonly used aluminum alloys in the automotive industry) in S-N curve. From Figure 4(f), the AZE911-T6 fatigue strength was very close to A356-T6 and A380-T6 alloys and as shown in Figure 4(e), the fatigue strength is very close for AZ91-T6 and A319-T6 in the range of $10^{4}-10^{6}$ cycles. On one hand, in the same cycle range, the difference between the fatigue strength of AZE911-T6 and both A356-T6 and A380-T6 alloys was much less than the difference in the HCF strength of AZE911, A356-T6, and A380-T6. On the other hand, the difference in the fatigue strength of AZ91-T6 and A319-T6 was less than the 


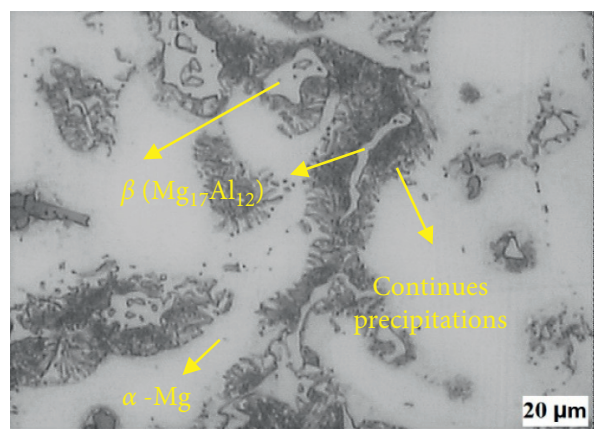

(a)

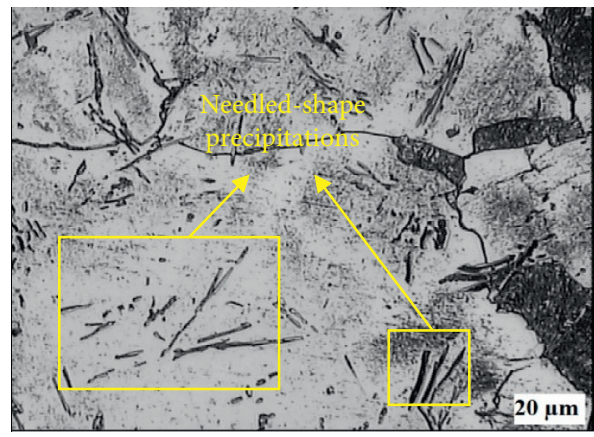

(c)

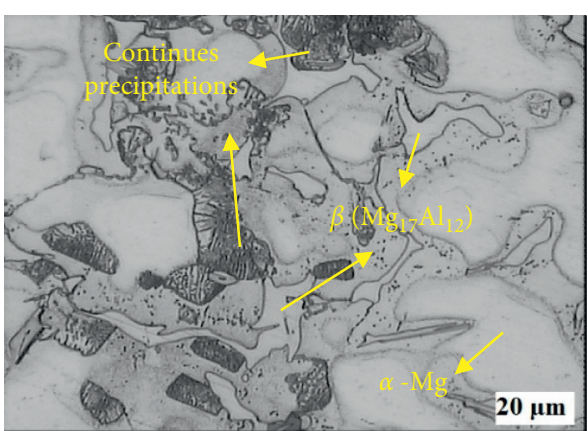

(b)

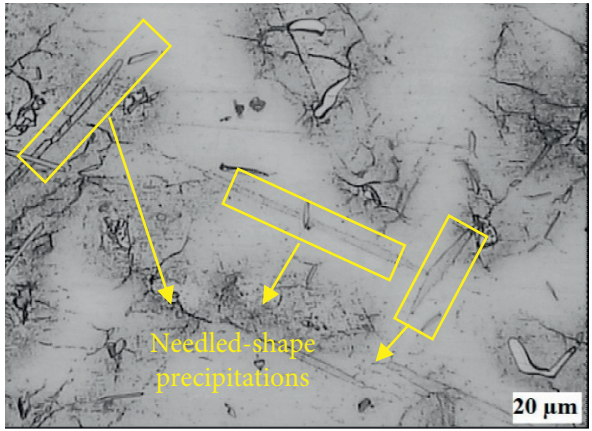

(d)

Figure 2: The microstructure of (a) AZ91, (b) AZE911, (c) AZ91-T6, and (d) AZE911-T6 alloys.

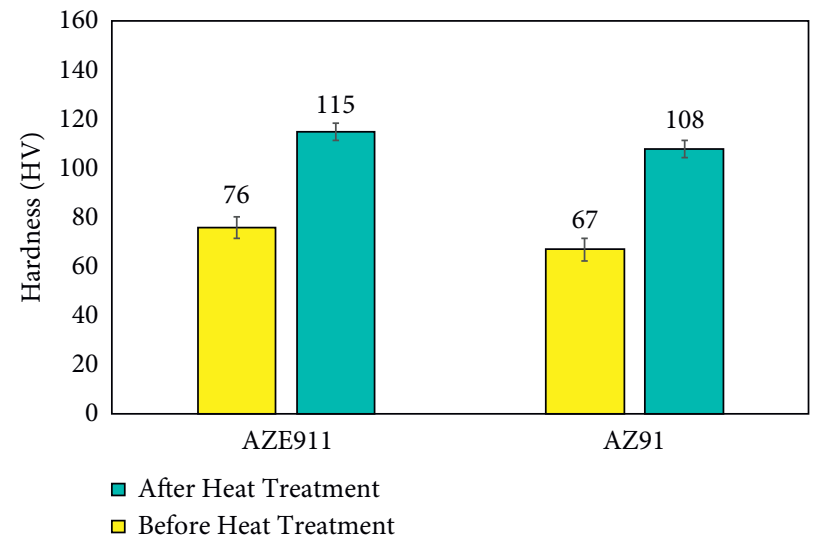

FIgURE 3: The effect of heat-treating on the hardness of AZ91 and AZE911 alloys.

difference in the fatigue strength of AZ91 and A319-T6. This means that, in terms of the fatigue strength, A356-T6 and A380-T6 aluminum alloys can be replaced with AZE911-T6, and the A319-T6 aluminum alloy can be substituted by AZ91-T6.

With this replacement, the weight of the cylinder head in diesel engines could be decreased by up to 50\% [19]. Moreover, several factors must be considered before performing the replacement approach on the cylinder head. These factors are mechanical properties under high-stress levels, the fatigue properties at high-stress levels, the allowable plastic strain, the corrosion strength, etc., through designing the component. For example, by the energy-based technique, Azadi et al. [24] estimated the fatigue lifetime of the cylinder head of diesel engines. They demonstrated that the fatigue lifetime was almost similar when A356-T6 was substituted with AZ61A [19].

Figure 4(b) shows the logarithmic scale of the maximum stress versus the strength limit. By extrapolating the curve equation from different data and a comparison of this formulation with the Basquin formulation, it is as follows [19]:

$$
\sigma_{a}=\sigma_{f}^{\prime}\left(2 N_{f}\right)^{b}
$$

where $\sigma_{a}$ is stress amplitude, $N_{f}$ is fatigue lifetime, $\sigma_{f}^{\prime}$ is the fatigue strength coefficient, and $b$ stands for the fatigue 

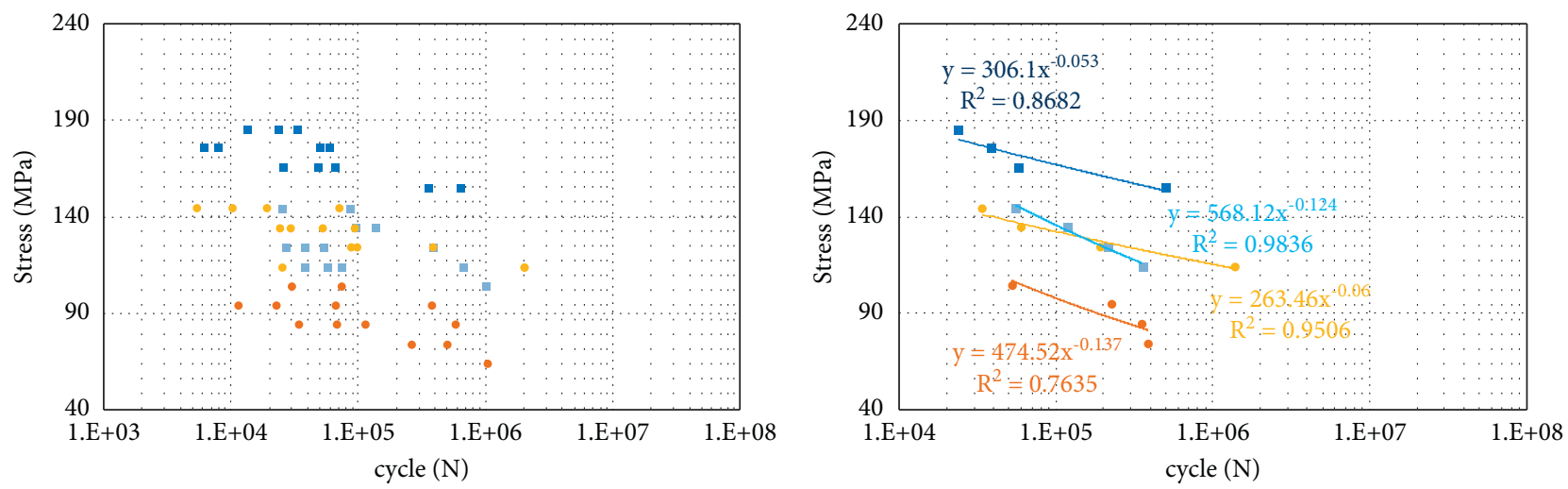

- AZ91-T6

- AZE911-T6

- AZ91

- AZE911

(a)

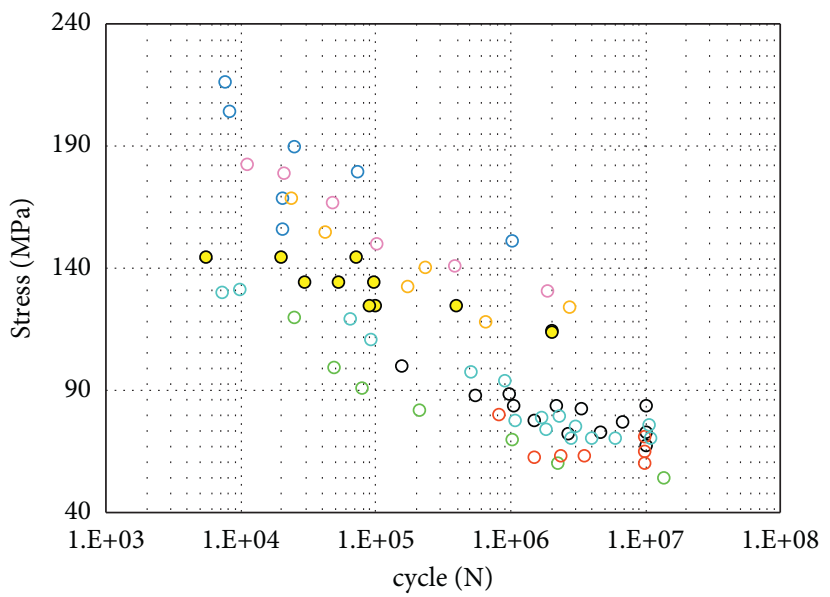

(c)

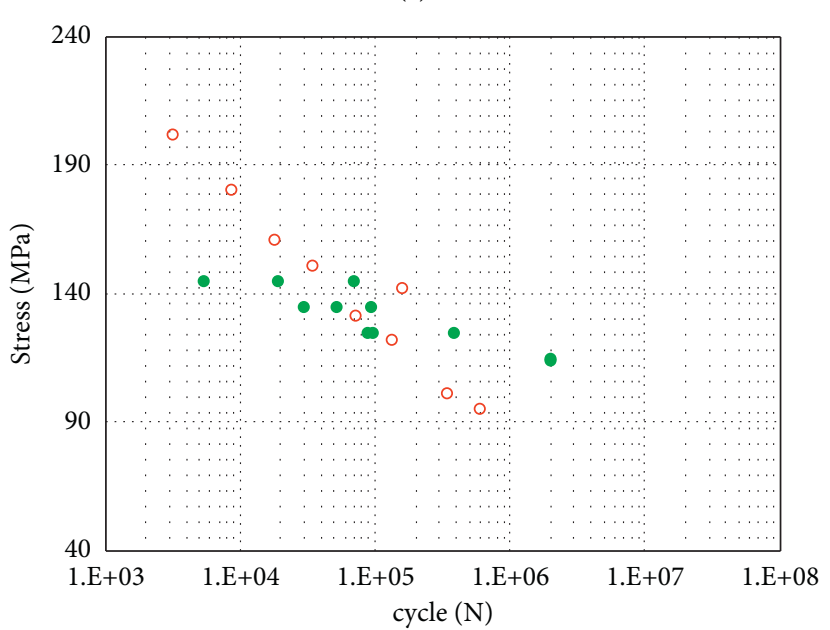

- A319-T6 [29]

- AZ91-T6

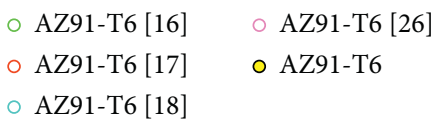

(c)

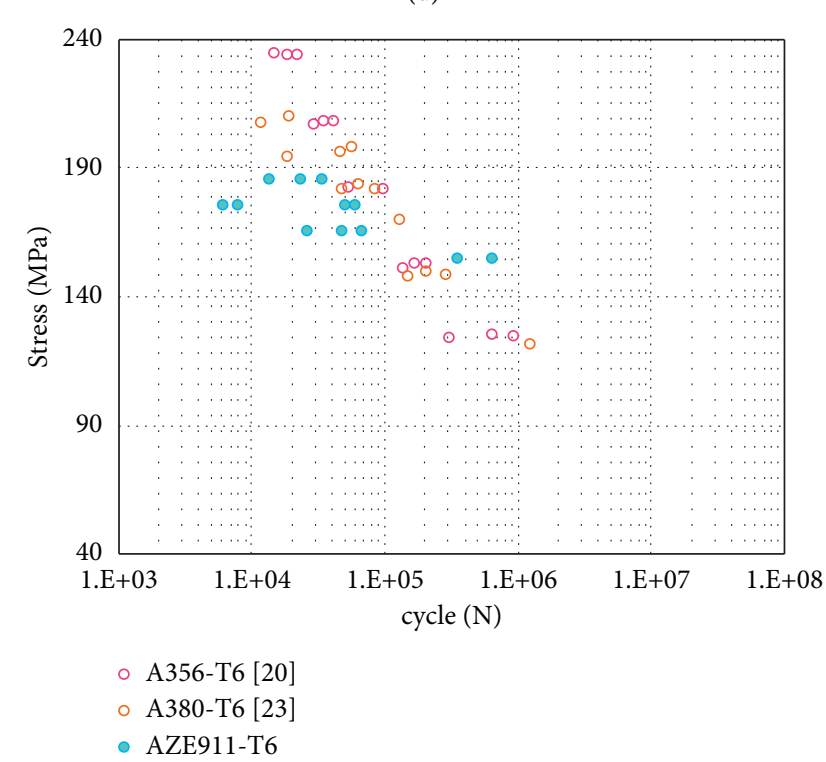

(e)

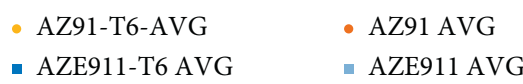

(b)

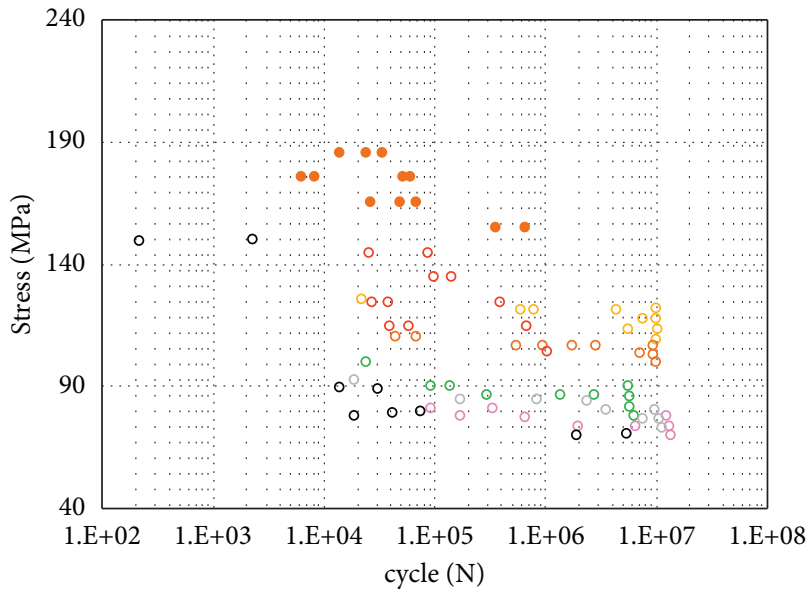

- $\mathrm{AZ91+2 \% Ce} \mathrm{[27]}$

- AZ91+1\%MM [28]

- AZ91+1\%RE [19]

- AZE911-T6

(d)

(f)

Figure 4: (a) All data, (b) averaged values, after and before heat treatment, and (c) the HCF behavior of AZ91-T6 in this research versus other research [7,9,16-18,20], (d) the HCF behavior of AZE911-T6 versus AZ91 containing rare earth Ce [27], Nd [4], MM [28], and RE, (e) the HCF behavior of AZ91-T6 versus A319-T6 [29], and (f) the HCF behavior of AZE911-T6 versus A356-T6 [25] and A380-T6 [26]. 
strength exponent, and the fatigue strength of alloys can be predicted in high fatigue cycles. As a note, the Basquin formulation can only be used for several cycles of less than $10^{6}$ cycles [19]. Therefore, the relationship in the S-N curve, on a logarithmic scale, for alloys including AZ91, AZ91-T6, AZE911, and AZE911-T6 can be calculated, which is reported in Table 3.

The fatigue strength of both AZ91 and AZE911 alloys in $3.8 \times 10^{5}$ cycles was equal to 95 and $125 \mathrm{MPa}$, respectively. Therefore, heat-treating on AZ91 and AZE911 resulted in a $31 \%(125 \mathrm{MPa})$ and $24 \%(155 \mathrm{MPa})$ increase in AZ91-T6 and AZE911-T6 alloys in $3.8 \times 10^{5}$ cycles, respectively.

As known, the growth of microcracks depends on cyclic plasticity, accumulation (stacking) of the fault energy, slip barriers such as grain boundaries, precipitates, secondary phases, and solute atoms that can create a threshold value for the growth of cracks [19]. Fen et al. [30] agreed with Yan and Wang [34] that reducing accumulated (stacking) fault is one of the probable reasons to have the proper fatigue strength of AZ91 alloys during the heat treatment. The other factors that affect the fatigue behavior of these alloys are porosities and inclusions. The heat treatment can refine the grain size by three reasons. First, the heat treatment usually causes more protrusion, making stand out and increase in the amount/number of grain boundaries. Increasing the amount/number of grain boundaries means the presence of more grains and the presence of more grains means the presence of smaller grains $[31,35]$. Second is increasing the microhardness of both Beta $\left(\mathrm{Mg}_{17} \mathrm{Al}_{12}\right)$ and Alpha phases (Mg matrix). Third is dissolving the precipitations of Beta $\left(\mathrm{Mg}_{17} \mathrm{Al}_{12}\right)$ phase in the $\mathrm{Mg}$ matrix grains [32]. As an important result, refining or decreasing the grain size and increase in the amount/number of grain boundaries are the main reasons to decreasing the fatigue cracks initiation from porosities and inclusions [33].

Moreover, AZ91 is the most susceptible $\mathrm{Mg}$-Al alloy for shrinkage (contraction) porosity. Thus, enough fatigue crack nucleation sites could be seen for this alloy. In addition, the heat treatment did not have a significant effect on the amount and distribution of inclusions and porosities of AZ91 and AZ91 + X\% + rare earth alloys, only better distribution and location of precipitations, which resulted in the reduction of fatigue cracking, the crack growth rate, from inclusions and porosities area (as fatigue crack nucleation sites) $[34,36,37]$. Therefore, any scientific report on the influence of heat-treating on the number of porosities and inclusions in AZ91 and AZ91 + X\% + rare earth alloys and its influence on the fatigue lifetime requires a large statistical work. Therefore, commenting on this factor is not reliable. Moreover, the reduction of the grain size and the formation of new needle-shaped precipitations within the gains of alpha phase in the microstructure of AZ91 and AZE911 alloys, which leads to a decrease in the fatigue crack growth, is responsible for increasing the fatigue strength of AZ91 and AZE911, after heat-treating.

Based on the microscopic evaluation on the fracture surface of samples, three distinct regions occur through the fatigue fracture, where there is a nucleus or crack initiation (region 1), crack propagation (region 2), and the final fracture (region 3), as shown in Figure 5(a) for the AZ91-T6
TABLE 3: Fatigue properties of studied cylinder head magnesium alloys.

\begin{tabular}{lcc}
\hline \multirow{2}{*}{ Alloys } & \multicolumn{2}{c}{ Using averaged values } \\
& $\sigma_{f}^{\prime}(\mathrm{MPa})$ & $b$ \\
\hline AZ91 & 474.52 & -0.137 \\
AZ91-T6 & 263.83 & -0.060 \\
AZE911 & 568.12 & -0.124 \\
AZE911-T6 & 306.1 & -0.053 \\
\hline
\end{tabular}

alloy and in Figure 5(b) for the AZE911-T6 alloy. In these figures, the arrows indicate the direction of crack propagation. In almost all specimens, fatigue cracks initiate beneath the surface of the material, according to cast defects. Macroscopic images of the fatigue fracture surface of AZ91T6 and AZE911-T6 alloys show two distinct fracture regions. It should be noted that Figures 5(a) and 5(c) show the surface fracture of the AZ91-T6 alloy with a stress level of $125 \mathrm{MPa}$ and a fatigue lifetime of $3.8 \times 10^{5}$ cycles and in Figures 5(b) and 5(d), the surface fracture of the AZE911-T6 alloy is shown with a stress level of $175 \mathrm{MPa}$ and a fatigue lifetime of $5 \times 10^{5}$ cycles. Fatigue surface fracture of AZ91-T6 and AZE911-T6 alloys has a completely brittle appearance. The presence of cleavages and quasicleavages, the more microcracks than the cracks, perpendicular to the direction of crack growth path to the direction of stress levels or force applied and silvery surface fracture caused a brittle fracture. Figures 5(c) and 5(d) show the cast defects area in the fracture surface of AZ91-T6 and AZE911-T6 alloys, respectively.

In Figure 6, further magnification of the fatigue crack area shows more structural details in region 2. As can be seen, the difference between this region for the AZE911-T6 alloy and the same region for AZ91-T6 is the presence of fine fatigue striations on the cleavages, and the presence of these striations can be observed in Figures 6(a) and 6(b).

Increasing the percentage of region 2 reduces the growth rate of cracks. Because none of the samples of the AZE911T6 alloy failed at the stress level tested for the AZ91-T6 alloy, it was not possible to compare the failure levels of the samples tested at the same stress level. In fact, the step-bystep growth of cracks in the area of fatigue crack growth has led to the formation of bands or, in other words, parallel striations due to the growth of fatigue cracks in the preferred direction in each grain (depending on the crystalline orientation). The fatigue steps of AZ91-T6 and AZE911-T6 are in the propagation zone of fatigue cracks (region 2). It is observed that the fatigue striations of both alloys become rough, although they were smooth and flat $[19,38,39]$. In addition, the size of the fatigue steps of AZE911-T6 becomes finer and the striations have a more irregular pattern than the AZ91-T6 alloy. No significant differences in the morphology of the collapse fracture (region 3 in Figures 6(c) and 6(d)) of AZ91-T6 and AZE911-T6 were observed in this study. In other words, the prominent effect of heat-treating is related to the area of the propagation of fatigue cracks and has a negligible influence on the fracture morphology of the fatigue striations fracture zone [7],[18],[40-43], Figure 6(c) 


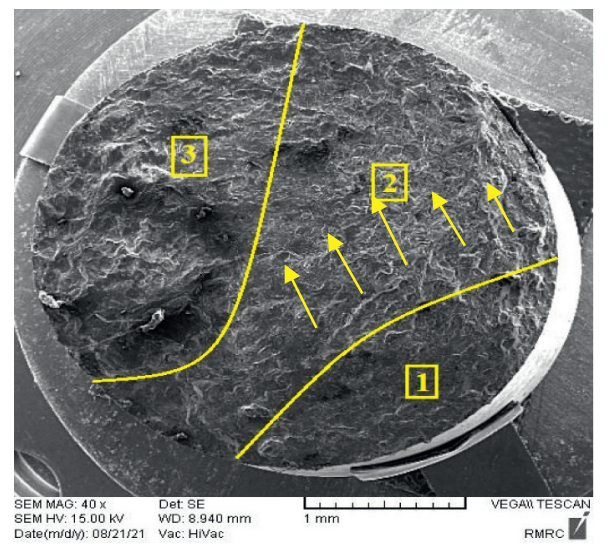

(a)

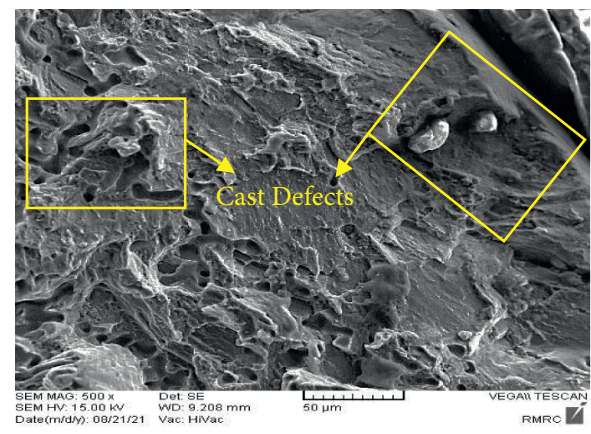

(c)

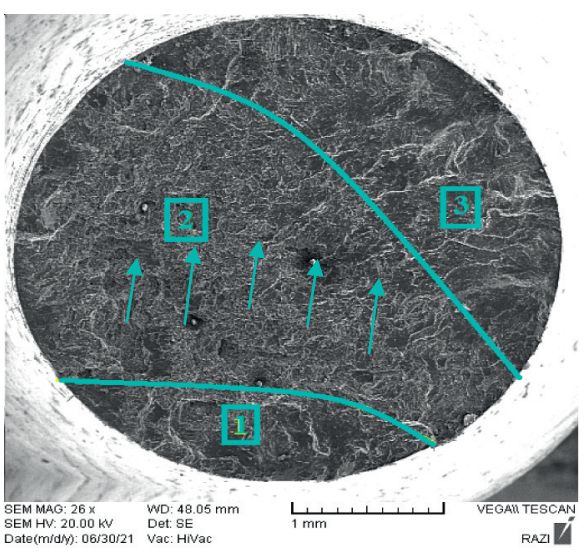

(b)

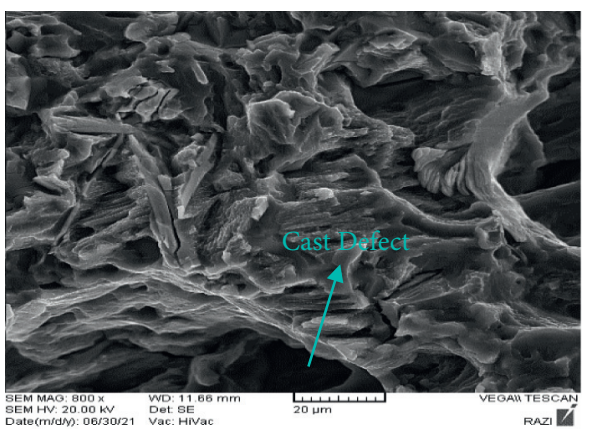

(d)

Figure 5: The fracture surface analysis of (a) AZ91-T6 and (b) AZE911-T6 and cast defects area in (c) AZ91-T6 and (d) AZE911-T6.

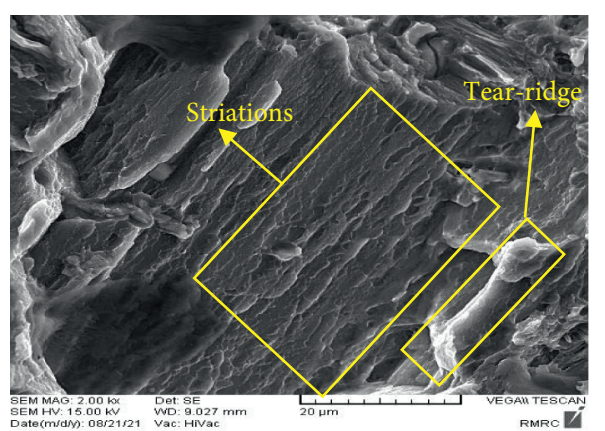

(a)

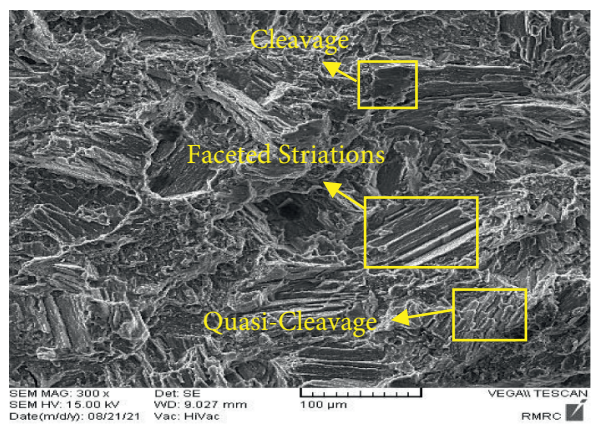

(c)

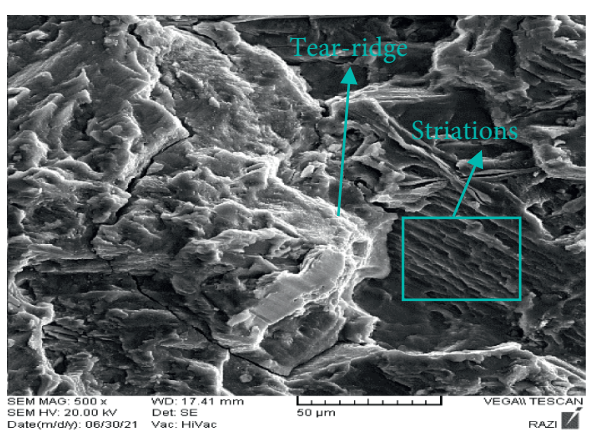

(b)

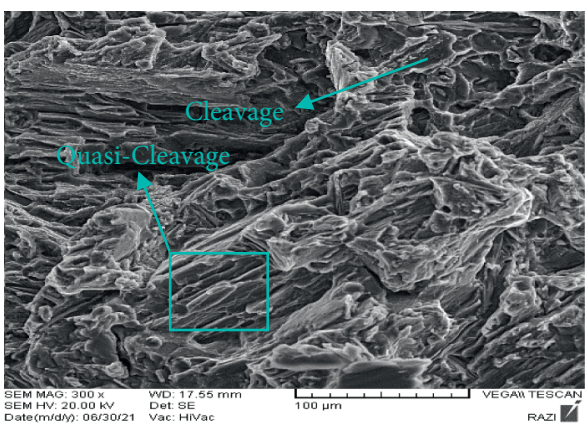

(d)

FIgURE 6: Continued. 


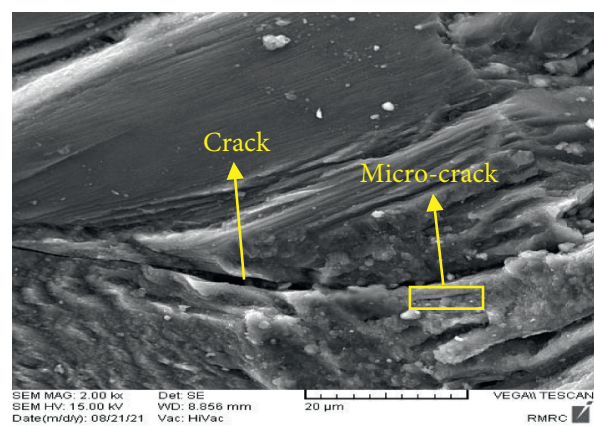

(e)

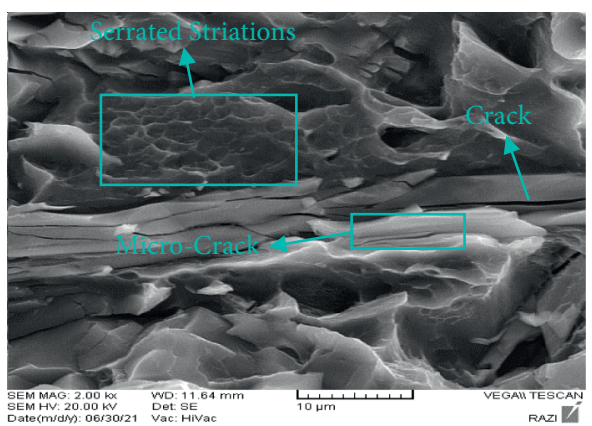

(f)

FIgURE 6: The morphology of tear-ridges and striations in the propagation region of fatigue cracks (region 2) of (a) AZ91-T6 and (b) AZE911-T6, cleavage and quasicleavage in the fracture region (region 3) of (c) AZ91-T6 and (d) AZE911-T6, and cracks and microcracks in the surface fracture (e) AZ91-T6 and (f) AZE911-T6.

shows a brittle fracture due to the presence of fine fatigue striations with faceted surfaces, and Figure 6(f) shows serrated fatigue striations propagation patterns.

It can be seen from the SEM analysis that AZ91-T6 showed a more brittle behavior than AZE911-T6 due to the following reasons:

(i) The size of cleavage marks in AZ91-T6 is much larger than that in AZE911-T6.

(ii) The values of quasicleavages in AZ91-T6 are much less than that in AZE911-T6.

(iii) The number of fatigue striations in AZ91-T6 is more than that in AZE911-T6.

The fracture of samples of the AZE911-T6 alloy at highstress levels can be attributed to the presence of continuous precipitations around the grains and a large number of grain boundaries (due to the decreasing grain size), which surrounded the grains like an outer wall and lead to deviation of the fatigue crack to some shorter cracks and even have a barrier role to the growth of fatigue cracks or microcracks, which results in a reduction of fatigue growth rate and long fatigue lifetime (at high-stress levels).

As the last point, for the further works, the transmission electron microcopy (TEM) could be used for a better understanding of microstructural changes in the material, after the heat treatment.

\section{Conclusions}

In the present article, HCF properties in AZ91 and AZE911 (cylinder head) magnesium alloys with and without heattreating were demonstrated. Then, obtained experimental data could be listed as follows:

(i) The hardness of the AZ91 alloy increased by $61 \%$ (67 to 108 Vickers) after ageing at $215^{\circ} \mathrm{C}$ for 3 hours and the hardness of AZE911 increased by $51 \%$ at $215^{\circ} \mathrm{C}$ for 5 hours (76 to 115 Vickers).

(ii) Optical microscopy (OM) examination showed that ageing treatments transform the continuous and discontinuous precipitations into needle-shaped precipitations. (iii) Significant reduction occurs in grain size from $300 \mu \mathrm{m}$ to $130 \mu \mathrm{m}$ for the AZ91 alloy and from $230 \mu \mathrm{m}$ to $90 \mu \mathrm{m}$ for the AZE911 alloy, after the heat treatment.

(iv) Scanning electron microscopy (SEM) showed brittle fracture behavior due to the presence of the cleavage and quasicleavage patterns on the specimen fracture surfaces. Besides, cleavage planes were smaller in heat-treated samples, which had influences on the fatigue strength and the lifetime of the alloy. However, the AZ91-T6 alloy shows a more brittle behavior than the AZE911-T6 alloy.

(v) Heat-treating significantly improved the strength limit (stress levels). Curves of stress-lifetime (S-N curves) show an enhancement in the fatigue strength at $3.8 \times 10^{5}$ cycles, from $95 \mathrm{MPa}$ to $125 \mathrm{MPa}$ for the AZ91-T6 alloy and from $125 \mathrm{MPa}$ to $155 \mathrm{MPa}$ for the AZE911-T6 alloy.

\section{Data Availability}

The experimental data used to support the findings of this study are included within the article.

\section{Conflicts of Interest}

The authors declare that they have no conflicts of interest.

\section{References}

[1] A. Tharumarajah and P. Koltun, "Is there an environmental advantage of using magnesium components for lightweighting cars?" Journal of Cleaner Production, vol. 15, no. Nos. 11-12, pp. 1007-1013, 2006.

[2] H. Hu, A. Yu, N. Li, and J. E. Allison, "Potential magnesium alloys for high-temperature die cast automotive applications: a Review," Materials and Manufacturing Processes, vol. 18, no. No. 5, pp. 687-717, 2003.

[3] S. Das, "Magnesium for automotive applications: Primary production cost assessment," Journal of Occupational Medicine, vol. 55, no. 11, pp. 22-26, 2003.

[4] Y. Yang and X. Li, "Influence of neodymium on high cycle fatigue behavior of die cast AZ91D magnesium alloy," Journal of Rare Earths, vol. 28, no. 3, pp. 456-460, 2010. 
[5] D. Wenwen, S. Yangshan, M. Xuegang, X. Feng, Z. Min, and W. Dengyun, "Microstructure and mechanical properties of Mg-Al based alloy with calcium and rare earth additions," Materials Science and Engineering, vol. 356, no. 1-2, pp. 1-7, 2003.

[6] R. Mahmudi, F. Kabirian, and Z. Nematollahi, "Microstructural stability and high-temperature mechanical properties of AZ91 and AZ91+2RE magnesium alloys," Materials \& Design, vol. 32, no. 5, pp. 2583-2589, 2011.

[7] M. Kuffova, "Fatigue endurance of magnesium alloys," Magnesium Alloys-Design, Processing and Properties, vol. 14, pp. 130-163, 1996.

[8] A. Bag and W. Zhou, "Tensile and fatigue behavior of AZ91D magnesium alloy," Journal of Materials Science Letters, vol. 20, no. 5, pp. 457-459, 2001.

[9] P. Zhang, Z. Li, and H. Yue, "Strain-controlled cyclic deformation behavior of cast Mg-2.99Nd-0.18Zn-0.38Zr and AZ91D magnesium alloys," Journal of Materials Science, vol. 51, no. 11, pp. 5469-5486, 2016.

[10] H. A. Hassan and J. J. Lewandowski, "Effects of particulate volume fraction on cyclic stress response and fatigue life of AZ91D magnesium alloy metal matrix composites," Materials Science and Engineering, vol. 600, pp. 188-194, 2014.

[11] L. A. Dobrzanski, T. Tanski, L. Cizek, and J. Madejski, "The influence of the heat treatment on the microstructure and properties of Mg-Al-Zn based alloys," Archives of Materials Science and Engineering, vol. 35, no. 2, pp. 5-11, 2009.

[12] M. Horstemeyer, N. Yang, K. Gall, D. L. McDowell, J. Fan, and P. M. Gullett, "High cycle fatigue of a die cast AZ91E-T4 magnesium alloy," Acta Materialia, vol. 52, no. 5, pp. 1327-1336, 2004.

[13] M. Govindaraju, R. Vaira Vignesh, and R. Padmanaban, "Effect of heat treatment on the microstructure and mechanical properties of the friction stir processed AZ91D magnesium alloy," Metal Science and Heat Treatment, vol. 61, no. 5-6, pp. 311-3117, 2019.

[14] D. G. Leo Prakash, D. Regener, and W. J. J. Vorster, "Effect of long term annealing on the microstructure of hpdc AZ91 Mg alloy: a quantitative analysis by image processing," Computational Materials Science, vol. 43, no. 4, pp. 759-766, 2008.

[15] C. Suman, "Heat treatment of magnesium die-casting alloys AZ91D and AM60B," The Engineering Society for Advancing Mobility Land Sea Air and Space, vol. 25, pp. 1-10, 2018.

[16] D. Dimitrov and V. Shtarbakov, "Ultrasonic fatigue test of AZ91 magnesium alloy," Machines, Technologies and Materials, vol. 1, pp. 138-141, 2013.

[17] H. Mayer, M. Papakyriacou, B. Zettl, and S. Vacic, "Endurance limit and threshold stress intensity of die cast magnesium and aluminium alloys at elevated temperatures," International Journal of Fatigue, vol. 27, no. 9, pp. 1076-1088, 2005.

[18] Z. Li, A. A. Luo, Q. Wang, H. Zou, J. Dai, and L. Peng, "Fatigue characteristics of sand-cast AZ91D magnesium alloy," Journal of Magnesium and Alloys, vol. 5, no. 1, pp. 1-12, 2017.

[19] M. Mokhtarishirazabad, S. M. A. Boutorabi, M. Azadi, and M. Nikravan, "Effect of rare earth elements on high cycle fatigue behavior of AZ91 alloy," Materials Science and Engineering, vol. 587, pp. 179-184, 2013.

[20] S. Rezanezhad, M. Azadi, and M. Azadi, "Influence of heat treatment on high-cycle fatigue and fracture behaviors of piston aluminum alloy under fully-reversed cyclic bending," Metals and Materials International, vol. 27, no. 5, pp. 860870, 2021.
[21] M. Azadi, "Cyclic thermo-mechanical stress, strain and continuum damage behaviors in light alloys during fatigue lifetime considering heat treatment effect," International Journal of Fatigue, vol. 99, pp. 303-314, 2017.

[22] S. Lee, S. H. Li, and D. H. Kim, "Effect of Y, Sr, and Nd additions on the microstructure and micro-fracture mechanism of squeeze-cast AZ91-X magnesium alloys," Metallurgical and Materials Transactions A, vol. 29, pp. 1998-1235, 2016.

[23] S. Khisheh, K. Khalili, M. Azadi, and V. Zaker Hendouabadi, "Influences of roughness and heat treatment on high-cycle bending fatigue properties of A380 aluminum alloy under stress-controlled cyclic loading," Materials Chemistry and Physics, vol. 264, pp. 1-13, 2021.

[24] M. Azadi, A. Mafi, M. Roozban, and F. Moghaddam, "Failure analysis of a cracked gasoline engine cylinder head," Journal of Failure Analysis and Prevention, vol. 12, no. 3, pp. 286-294, 2012.

[25] M. S. Aghareb Parast, M. J. Khameneh, M. Azadi, M. Azadi, M. H. Mahdipanah, and S. Roostaie, "Effect of plasma nitriding on high-cycle fatigue properties and fracture behaviors of GJS 700 nodular cast iron under cyclic bending loading," Fatigue and Fracture of Engineering Materials and Structures, vol. 44, pp. 1-17, 2021.

[26] H. Bahmanabadi, S. Rezanezhad, M. Azadi, and M. Azadi, "Characterization of creep damage and lifetime in Inconel713C nickel-based superalloy by stress-based, strain/strain rate-based and continuum damage mechanics," Journal of Materials Research, vol. 5, pp. 1-34, 2018.

[27] Y. Yang, Y. Liu, S. Qin, and Y. Fang, "High cycle fatigue properties of die-cast magnesium alloy AZ91D with addition of different concentrations of cerium," Journal of Rare Earths, vol. 24, no. 5, pp. 591-595, 2006.

[28] Y. L. Xu, K. Zhang, X. Li, J. Lei, Y. S. Yang, and T. J. Luo, “High cycle fatigue properties of die-cast magnesium alloy AZ91D1\%MM," Transactions of Nonferrous Metals Society of China, vol. 18, pp. 306-311, 2008.

[29] K. J. Kim and C. H. Jeong, "Effect of microstructure on hightemperature mechanical properties of A319 casting alloy for automotive cylinder heads," Materials Transactions, vol. 57, no. 5, pp. 738-747, 2016.

[30] G. Fen, L. Pengfei, G. Xia, and X. Juan, "Study on the solid solution and ageing process of AZ91D magnesium alloy with cerium," Journal of Rare Earths, vol. 28, no. 6, pp. 948-951, 2010.

[31] C. Li, M. Z. M. Zamzuri, S. Norbahiyah, K. A. Ismail, M. N. B. Derman, and S. Illias, "Effect of heat treatment on microstructure and corrosion behavior of AZ91D magnesium alloy," Advanced Materials Research, vol. 685, pp. 102-106, 2013.

[32] Z. M. Li, Q. G. Wang, A. A. Luo, L. M. Peng, P. H. Fu, and Y.X. Wang, "Improved high cycle fatigue properties of a new magnesium alloy," Materials Science and Engineering, vol. 582, pp. 170-177, 2013.

[33] Y. Yang, H. Wu, and X. S. Li, "High cycle fatigue behavior of gravity cast AZ91D magnesium alloy," Materials Science Forum, vol. 686, pp. 157-161, 2011.

[34] H. Yan and Z. Wang, "Effect of heat treatment on wear properties of extruded AZ91 alloy treated with yttrium," Journal of Rare Earths, vol. 34, no. 3, pp. 308-314, 2016.

[35] L.-j. Yang, Y.-h. Wei, and L.-f. Hou, "Microstructure evolution of thixomolding AZ91D magnesium alloy during heat treatment," Journal of Materials Science, vol. 45, no. 13, pp. 3626-3634, 2010. 
[36] Z. Trojanová, P. Palček, M. Chalupová, P. Hlaváčová, and I. Hlavacova, "High frequency cycling behaviour of three AZ magnesium alloys - microstructural characterisation," International Journal of Materials Research, vol. 107, no. 10, pp. 903-915, 2016.

[37] S. Fintová and L. Kunz, "Fatigue properties of magnesium alloy AZ91 processed by severe plastic deformation," Journal of the Mechanical Behavior of Biomedical Materials, vol. 42, pp. 219-228, 2015.

[38] M. Papakyriacou, H. Mayer, U. Fuchs, S. E. Stanzl-tschegg, and R. P. Wei, "Influence of atmospheric moisture on slow fatigue crack growth at ultrasonic frequency in aluminium and magnesium alloys," Fatigue and Fracture of Engineering Materials and Structures, vol. 25, no. 8-9, pp. 795-804, 2002.

[39] M. Kumar, K. N. S. Suman, P. Poddar, and T. Sasan, "Performance evaluation of surface modified nano $\mathrm{Al}_{2} \mathrm{O}_{3}$ reinforced AZ91 composites under impact and fatigue loading conditions," Journal of Mechanical Engineering, vol. 70, no. 1, pp. 29-38, 2020.

[40] Z. Sun, X. Geng, L. Ren, and H. Hu, "Microstructure, tensile properties and fracture behavior of HPDC magnesium alloy AZ91," International Journal of Machining and Machinability of Materials, vol. 8, no. 2, pp. 50-56, 2020.

[41] A. Nemcova, J. Zapletal, M. Julis, and T. Podrabsky, "Cyclic fatigue resistance of AZ91 magnesium alloy," Materials Engineering, vol. 16, no. 4, 2009.

[42] D. Tie, Y. Jiang, R. Guan et al., "The evolution of microstructure, mechanical properties and fracture behavior with increasing lanthanum content in AZ91 alloy," Journal of Metals, vol. 10, no. 1256, pp. 1-11, 2020.

[43] A. R. Vaidya and J. J. Lewandowski, "Effects of SiCp size and volume fraction on the high cycle fatigue behavior of AZ91D magnesium alloy composites," Materials Science and Engineering, vol. 220, no. 1-2, pp. 85-92, 1996. 